Phonology 38 (2021) 123-146. (C) The Author(s), 2021. Published by Cambridge University Press. This is an Open Access article, distributed under the terms of the Creative Commons Attribution licence (http://creativecommons.org/licenses/by/4.0/), which permits unrestricted re-use,

distribution, and reproduction in any medium, provided the original work is properly cited. doi:10.1017/S0952675721000063

\title{
Polarity in a four-level tone language: tone features in Tenyidie*
}

\author{
Savio M. Meyase \\ University of Leipzig
}

\begin{abstract}
This paper reports a new kind of tone polarity, where the phenomenon is seen in a language with four level tones, Tenyidie (also known as Angami). I show that the polarity is in the features of the tones, i.e. at a subtonal level. The data also provide evidence that tones themselves can be broken down into smaller features. Furthermore, I demonstrate that the polarity pattern observed in the language is an epiphenomenon, a reflex of the Obligatory Contour Principle, not a phonological process in its own right. I show this with the help of a new type of tonal representation. Theoretical discussions of tone polarity have so far been almost entirely restricted to African tone systems, and to languages with just two tones. This paper brings into the discussion a Tibeto-Burman language with four tones.
\end{abstract}

\section{Introduction}

Tone polarity is the pattern where a tone-bearing unit (TBU) $y$ has a tonal value which is the opposite of that of an immediately adjacent TBU $x$; TBU $y$ is generally an affix. Mainstream theoretical discussions on tone polarity have so far been almost exclusively based on African languages. ${ }^{1}$ The classic example is Mòoré (also known as Mossi), reported by

* E-mail: SAVIO.MEYASE@UNI-LEIPZIG.DE.

Many thanks to the anonymous reviewers, the associate editor and the editors of Phonology for constructive comments and recommendations. I thank the Deutsche Forschungsgemeinschaft for funding my research. Thanks to the researchers at Leipzig for their help, and special thanks to Yuni Kim for all the support and the additional help given.

1 African languages reported to show tone polarity are the following: Afro-Asiatic: Hausa (Newman 1995), Margi (Hoffmann 1963, Pulleyblank 1983), Ngizim (Schuh 1971); Niger-Congo: Dagbani (Olawsky 1996), Dagaare (Anttila \& Bodomo 2000), Konni (Cahill 2004), Lama (Kenstowicz et al. 1988), Mòoré (Kenstowicz et al. 1988), Bambara (also known as Bamana; Dwyer 1976, Creissels \& Grégoire 1993), Mono (Olson 2001), Gokana (Hyman 1985), Igbo (Welmers \& Welmers 1968), Yoruba (Akinlabi \& Liberman 2000); Nilo-Saharan: Fur (also known as Konjara; Lojenga 2002), Kanuri (Cyffer 1991, Trommer 2005); Bangime (isolate; Hantgan 2009). 


\section{Savio M. Meyase}

Kenstowicz et al. (1988), where the tone on the number suffix is always the opposite of that on the noun, as in (1). (Mòoré has two tones: high, indicated in (1) by the diacritic $/ \%$, and low, which is left unmarked.)

$\begin{array}{lll}\text { (1) singular } & \text { plural } & \\ \text { kor-gó } & \text { kor-dó } & \text { 'sack' } \\ \text { ro:-gó } & \text { ro-tó } & \text { 'house' } \\ \text { wób-go } & \text { wób-do } & \text { 'elephant' } \\ \text { lán-go } & \text { lán-do } & \text { 'hole' }\end{array}$

Despite tone polarity being considered typically an African property, there are other tone languages that display the phenomenon. Mundurukú (Picanço 2002), spoken in Brazil, is probably the only one reported in the Americas. Sylheti (Mahanta \& Gope 2018), an Indo-European language spoken in eastern India, has also been reported to display tone polarity. Three Tibeto-Burman languages have recently been identified as displaying the same phenomenon: Anál (Ozerov 2018), Myebon Sumtu Chin (Watkins 2013) and Thadou (also known as Kuki-Thadou; Hyman 2007). The Qiangic languages Mianchi Qiang (Evans 2008) and Zhuokeji Rgyalrong (also known as Jiarong; Lin 2012) have been claimed to have tone polarity, but these display a tone change in the same morpheme in word formation, rather than surface tone polarity, and are not really an example of the same phenomenon.

Tone polarity has almost always been discussed with respect to two-way tone systems. All the above languages, African and non-African, are systems with only two tones, apart from three which have three tones: Yoruba, Mono and Gokana. Of these, Yoruba has been argued to have only two phonological tones, with the 'third' tone being the absence of phonological tone (Akinlabi \& Liberman 2000), while the tone polarity patterns in both Mono and Gokana are rather restricted, and are seen in only one morpheme in each language.

In this paper I show that tone polarity is seen in the Tibeto-Burman language Tenyidie (/tēnīdiē $/{ }^{2}$ also known as Angami), which has a four-tone system. The analysis of polarity in a four-tone language is not as straightforward as it is in a two-tone language, because the very notion of polarity entails just two categories. I argue that, if the four tones of Tenyidie are decomposed into two polar features, polarity can be shown to operate at a subtonal level. The data provides evidence that tones can be broken down into smaller features, supporting McPherson (2010), but arguing against Hyman (2010) and Clements et al. (2010), who are sceptical of tone features.

There is a long-standing debate in phonology over whether polarity is a process sui generis or just an epiphenomenon of other linguistic processes. While scholars like Gregersen (1974) see polarity as a phonological operation relying on powerful mechanisms like alpha rules, others, like de Lacy

2 In diphthongs such as $/ \mathrm{ie} /$, tone is marked on the second element, which is more prominent. 
(2012), have argued that it is merely a secondary consequence of other phonological operations, such as the Obligatory Contour Principle (OCP). In this paper, I show that the Tenyidie case is better analysed as an epiphenomenon resulting from the operation of the OCP. Crucially, I will also argue that Tenyidie provides new evidence for the use of subtonal autosegmental representation, and show the derivation of the various tonal phenomena simply falls into place using already available phonological tools.

In $\$ 2$, I present the language and the data illustrating tonal natural classes and the polarity pattern. $\S 3$ provides my analysis, with the help of a novel autosegmental tonal representation based on two hierarchically organised nodal tone tiers (register and melody), each associated to the same subtonal feature set, $\mathrm{H}$ and $\mathrm{L}$, which allows for the interaction between tiers without disrupting their structural positions. I present my analysis in the framework of standard parallel Optimality Theory (OT). In $\S 4$, I discuss other possible approaches and tone representations for the polarity data. In $\S 5$, I consider the case of Tenyidie as an addition to the empirical and theoretical discussion. $\$ 6$ provides more data on the interaction of the tones in the language with respect to multiple suffixes, showing that the observed polarity is independent of the stem-affix environment, against the general view on polarity.

\section{The language and data}

Tenyidie, also known by the exonym Angami (ISO: njm), is a TibetoBurman language spoken by the Angami tribe in the district of Kohima in the Indian state of Nagaland, which is part of the Himalayan range separating India from Myanmar. All the data is from the author's fieldwork from the last ten years, and are presented in Meyase (2014, 2016); the polarity pattern is also presented there, but not mentioned explicitly. The 2014 study includes data from two female Tenyidie speakers born and raised in Kohima Town, who were then university students aged 25 and 29; the 2016 study includes data from the previous two speakers, as well as acoustic data from six other Kohima-resident Tenyidie speakers, aged between 20 and 25 at the time of recording. The author is a native speaker of Tenyidie, also born and raised in Kohima Town, and their native speaker intuitions also contributed to the data collection process. Speakers of Tenyidie from Kohima over the age of 50 were also consulted to check the data.

There are four lexically distinctive level tones in Tenyidie, as shown in (2).

(2) Extra High High

Mid

Low

zé 'to wrap',
zé 'to pierce'
zè 'to sell'
zè 'to sleep'

da̋ 'to chop'

dá 'to pack'

dā 'to blame'

dà 'to paste'

Grammarians of the language (e.g. Kuolie 2006) describe it as having five tones, but only four tones are acoustically reported in phonetic studies 


\section{Savio M. Meyase}

(Dutta et al. 2012), just as in the related variety of Khonoma (Blankenship et al. 1992). However, phonologically it has a fifth contour/cluster tone, comprised of High followed by a floating Mid, where the complex tone sounds like a High tone but behaves like a Mid tone (see Meyase 2014 for discussion and analysis). The fifth tone is not considered in this study, since it behaves in the same way as the Mid tone with respect to suffixes.

Moving on to the data under discussion in this paper, there are three types of suffixes in Tenyidie, based on their tonal behaviour. I refer to them as the 'non-alternating suffixes' (see (3) below), the 'assimilating suffixes' (4) and the 'quirky alternating suffixes' (5).

Firstly, the set of non-alternating suffixes in (3) display no tonal alternations at all, and suffixes with all the four lexical tones are found. We see all the tones in the stem on the syllable ze/ze/, giving four distinctive words, followed by the prospective suffix -zhie/zië/, which bears an Extra High tone, the perfective -shü / Já/, bearing a High tone, the imperative -cie /ciēe, with a Mid tone, and the progressive -tha $/ \mathrm{t}^{\mathrm{h}} \mathrm{a} /$, with a Low tone.

(3) Non-alternating suffixes
a. zê-zie̋ 'to wrap-Pros'
zé-zië 'to pierce-Pros'
c. ze̋-ciē 'to wrap-IMP'
zē-zië 'to sell-pros'
zé-ciē 'to pierce-IMP'
zè-zië 'to sleep-Pros'
$z \overline{\mathrm{e}}-\mathrm{cie \overline { \textrm {e } }}$ 'to sell-IMP'
b. ze̋-Já 'to wrap-PFV'
zé-fá 'to pierce-PFv'
zè-ciē 'to sleep-IMP'
zēelá 'to sell-PFv'
zè- $\int a ́$ 'to sleep-PFv'
d. zê-thà 'to wrap-PRog'
$z$ zé-thà 'to pierce-PROG'
$z \bar{e}-t^{\text {hà }}$ 'to sell-Prog'
zè-thà 'to sleep-Prog'

In (4) we have the same set of stems as in (3), but now followed by the progressive suffix $-z h \ddot{u} / 3 \mathrm{z} /$ and the perfective suffix $-t a / \mathrm{ta} /$. Unlike the set of non-alternating suffixes, the tone of these suffixes alternates between Extra High and High. The suffixes shows partial adoption of tonal height from the stem, hence the term 'assimilating suffixes'. In the first two forms in each subset, the tone of the suffix is an exact copy of that of the stem. This is not the case in the other two forms, but even in these two the tonally higher stem also has a higher tone on the suffix, i.e. Mid on the stem triggers Extra High on the suffix, and Low triggers High. I will show below that this is a case of assimilation at a subtonal level.

(4) Assimilating suffixes
a. ze̋-zə̋ 'to wrap-PRoG'
zé-zá 'to pierce-PROG'
b. ze̋-ta̋ 'to wrap-PFv'
$z \overline{\mathrm{e}}-3$ ’ 'to sell-PROG'
zé-tá 'to pierce-PFV'
zè-zว́ 'to sleep-PROG'
$z \bar{e}-$ ta̋ 'to sell-PFv'
zè-tá 'to sleep-PFv' 
Other suffixes of this type are another perfective marker, -te, and another progressive marker, $-b a$.

The set of 'quirky alternating suffixes' in (5) represents the essential data for tone polarity. As pointed out in $\S 1$, this set seems to display some kind of polarity - Extra High and High on the stem triggers Low on the suffix, and Low triggers Mid. The Mid tone on the stem triggers the same tone in the suffix. Thus the irrealis suffix -lie/lie/ in (5a) alternates in tone between Mid and Low, but displays a pattern which is different from (4). The negation marker -mo and the prohibitive -hie are also suffixes of this type, as is the progressive marker -tuo and the homophonous future marker-tuo. The alternation is again seen at a lower tone level; this will be discussed in $\S 3$.

(5) Quirky alternating suffixes
a. zë-liè 'to wrap-IRR'
zé-liè 'to pierce-IRR'
$z \overline{\mathrm{e}}-\mathrm{lie}$ 'to sell-IRR'
zè-liē 'to sleep-IRR'
b. zé-hiè 'to wrap-PROH'
zé-hiè 'to pierce-PROH'
$z \overline{\mathrm{e}}-\mathrm{hie} \overline{\mathrm{e}}$ 'to sell-PrOH'
zè-hiē 'to sleep-ProH'

The alternation in (5) is not restricted to the verb-suffix environment, but can also be found in nominal suffixes. For example, the singular nonfemale (default gender) definite marker $-u$ shows the same pattern of alternation, as shown in (6). In addition, the negation marker -mo, which also displays 'quirky' tonal behaviour, can follow both verbals and nominals.

(6) Quirky alternating noun suffix

$\begin{array}{ll}\text { sî-ù } & \text { 'stick-sG.DEF' } \\ \text { kēví-ù 'good (N)-SG.DEF' } & \text { bū-ù 'container-sG.DEF' } \\ \text { miè-ū 'person-sG.DEF' }\end{array}$

An inference that can be drawn from the datasets in (3)-(6) is that the nonalternating suffixes in (3) are fully specified for tone, and are therefore immune to tonal changes, regardless of the tone in the stem. On the other hand, the two kinds of suffixes in (4) and (5) are underspecified for some subtonal feature(s), and alternate based on the type of underspecification they have, influenced by the tone in the stem. This forms the basis of my argument for tone features.

\section{Analysis}

\subsection{Representation}

The data in the assimilating suffix set in (4) and the quirky alternating suffix set in (5) shows complex tonal change patterns; the tone changes are, however, systematic. In the assimilating suffix set, while there are 


\section{Savio M. Meyase}

cases of complete assimilation of tones, there are also cases in which the phonetic height of the tones is incompletely assimilated.

To analyse the intricacies of the patterns, let us first break the two sets down into smaller sets. The first two instances in the assimilation suffix data in (4a) are repeated as (7a).

$$
\begin{aligned}
& \text { a. zë-ză 'to wrap-PROG' } \\
& \text { zé-zá 'to pierce-Prog' }
\end{aligned}
$$

$$
\begin{aligned}
& \text { b. zē-z’à 'to sell-PROG' } \\
& \text { zè-zá 'to sleep-PROG', }
\end{aligned}
$$

As noted in $\S 2$, there is an apparently complete assimilation of the tones from the stem to the suffix: Extra High and High trigger the same tones in the suffix.

The case is different in the other two examples from (4a), repeated in (7b), where a Mid stem triggers an Extra High in the suffix, and Low triggers a High. However, there is still a partial assimilation of phonetic height - the higher tone in the stem triggers the higher tone in the suffix, and the lower tone in the stem trigger the lower one in the suffix.

In both (7a) and (b), it can be observed that the tones in the resultant suffix, although not identical, are consistently in the upper half of the tonal spectrum. The inference is that the two higher tones of the language have something in common. At the same time, the two higher stem tones in (7a) and (7b) are related (since they trigger the same tone on the suffix), as are the two lower suffix tones in the sets. This allows us to identify the following natural distinctions: (a) Extra High and High vs. Mid and Low, and (b) Extra High and Mid vs. High and Low. In other words, each of these pairs forms a natural class. As a result, representing the four tones of the language as four individual indivisible atoms is inadequate. This leads in turn to the need to decompose tones into smaller features, as has been previously argued for four-way tonal systems by, for example, Yip (1980), Clements (1983), Pulleyblank (1986) and Snider (1999)

For the purpose of this analysis, I propose the use of a tonal model in which the register tier and the pitch/tone/melody tier (henceforth the 'melody' tier, in order to avoid confusion between the lexical tones and the 'tone' tier) can interact with each other. A similar model can be found in Hyman's (1993) autosegmental representation of tones. However, Hyman's model is for a two-way tone system, and does not involve the decomposition of tones into smaller features. In the model proposed here, the TBU dominates the TONAL ROOT NODE (TRN), represented as $\bullet$, which in turn dominates and is associated to the TONAL NODE (TN), represented as $\circ$. The TRN and the TN are then associated to the register feature and the melody feature respectively. In the representation in (8), the four tones of Tenyidie are raised and lowered versions of the melodies $\mathrm{H}$ and $\mathrm{L}$. $\mathrm{H}$ and $\mathrm{L}$ are subtonal features, not whole tones. Register $\mathrm{H}$ raises the pitch, and register L lowers the pitch. 
(8) Autosegmental representation of the four tones of Tenyidie
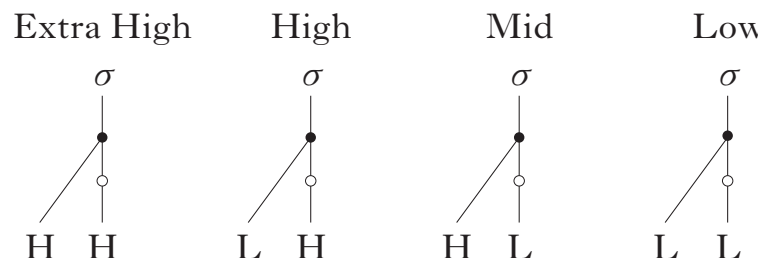

tonal root node (TRN) tonal node $(\mathrm{TN})$

In (8), Extra High and High have a melody feature $\mathrm{H}$ each linked to the TN (which forms the melody feature); this is the feature common to both tones. They are distinguished by the different features linked to the TRN. If the TRN is linked to another occurrence of $\mathrm{H}$ (the register feature), this raises the $\mathrm{H}$ associated with the $\mathrm{TN}$, forming an Extra High tone. On the other hand, an $\mathrm{L}$ linked to the TRN lowers the $\mathrm{H}$ associated with the TN, resulting in a High tone.

The crucial difference between my proposed representation and Hyman's is that, for Hyman, the tone/feature on the register node is not an inherent property of the tone the TBU is associated to; rather, it is an independent whole tone that plays a role only when it is in contact with neighbouring tones. In my representation, however, the feature (rather than the tone) on the register node is inherently a property of the tone.

The analysis of Mid and Low tones is similar, the difference being that the TN is associated with an L. For Mid, the $\mathrm{L}$ is raised by the $\mathrm{H}$ associated with the TRN; for Low, it is lowered by the L associated with the TRN. We then have four distinct configurations for the four tones in the language, using the traditional features of tone, $\mathrm{H}$ and $\mathrm{L}$.

An important aspect of these configurations, following Hyman, is that the projections of the nodes TRN and TN are on different planes, and therefore the linear order of the tone features within a syllable (i.e. within the TBU) does not play a role.

3.1.1 The representation of assimilating suffixes. Using the representations proposed above, if we assume that an assimilating suffix is specified for the TN but has no specification for the TRN, we can derive the observed alternation as a spreading of the feature in the TRN from the stem to the suffix, as for [zē-zz̋] in (9). Since the register and the melody are on different planes, the $\mathrm{H}$ in the register of the stem syllable is free to spread onto the next empty register node without crossing any association line.

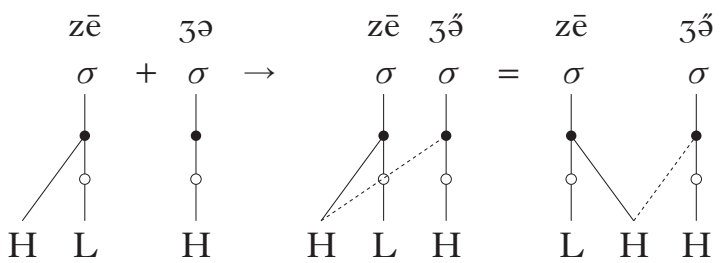




\section{Savio M. Meyase}

The process of spreading is the same for [zè-ż́], where the TRN is L. This spreads on to the same underspecified suffix, yielding a High tone, rather than Extra High.

3.1.2 The representation of quirky alternating suffixes. The behaviour of the quirky alternating suffixes in (5) is in some respects the reverse of that of the assimilating suffixes in (4). In (5) the tone of the suffix is always in the lower regions of the tonal domain - Mid and Low - regardless of the tone in the stem. This provides further support for the proposed model, in which the two lower tones form a natural class which excludes the two higher tones.

Using the representations proposed here, this pattern can be analysed as a case of epenthesis-driven surface dissimilation. In (10a) (repeated from (5a) above), the two higher tones trigger the lowest tone, Low, and in (b), the two lower tones trigger a higher tone, Mid.
a. zë-liè 'to wrap-IRR'
zé-liè 'to pierce-IRR'
b. zē-liē 'to sell-IRR'
zè-liē 'to sleep-IRR'

Like the assimilating suffix, the suffix here is unspecified for the TRN, but it is specified as $\mathrm{L}$ for the TN, as is evident from the fact that the tone on the suffix is always in the lower range of the spectrum.

This set behaves oddly in not having a straightforward operation to explain the outcome. For the forms in (10b), we have the output structure in (11a), where the empty TRN is associated to $\mathrm{H}$.

a.

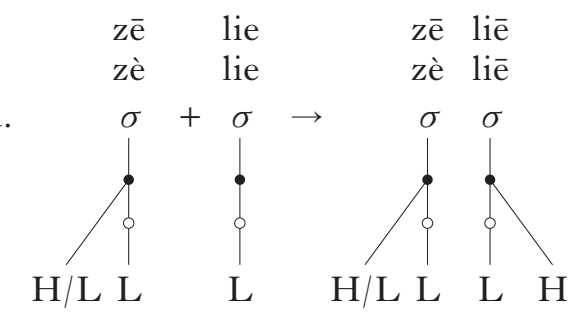

b.

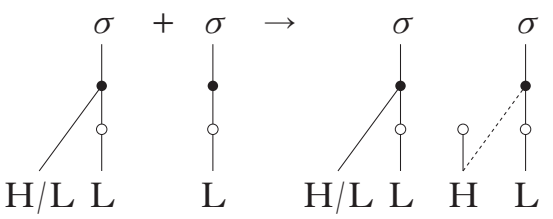

I propose that this epenthesis of $\mathrm{H}$, and ultimately the polarity pattern, is because of the OCP restriction between the TNs bearing the $\mathrm{L}$ feature. This comes into play only when the stem is a Mid or a Low - one with an $\mathrm{L}$ in the $\mathrm{TN}$. In order to satisfy the OCP, we epenthesise a TN bearing an $\mathrm{H}$, as shown in (11b). The advantage of the representation proposed here is that we can assume a constraint, $\mathrm{OCP}(\circ-\mathrm{L})$, which prohibits two adjacent TNs dominating Ls, and is satisfied by the insertion of a TN 
associated with $\mathrm{H}$, which is linked to the unspecified TRN to give the desired output. (A formal definition of $\mathrm{OCP}(\circ-\mathrm{L})$ is given in (20) below.) In a representation without nodes, a simple $\mathrm{OCP}(\mathrm{L})$ constraint would force the insertion of just an $\mathrm{H}$, which would then have to somehow move to a different plane or tier altogether. The advantage of a representation with nodes is that they always remain on their tiers; it is only the associations that change. It is the OCP effect and the crossplane interaction which make this set 'quirky'.

For the two cases in (10a), the OCP is not relevant, and the requirement to fill the empty node is simply fulfilled by epenthesis of a default L, as in (12).

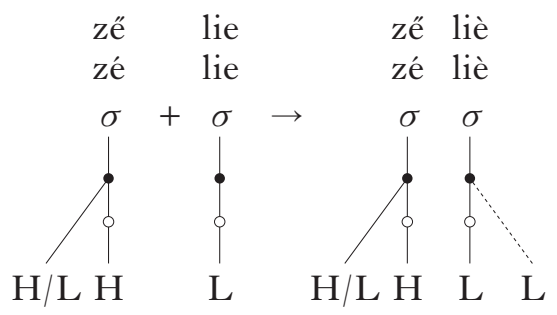

A question that arises is whether we are still dealing with polarity in this case. On the surface, we are. In (11b) the epenthesised tone feature is $\mathrm{H}$ in the suffix, a result of the OCP violation in the stem. In (12), the epenthesised tone feature is $\mathrm{L}$ in the suffix, a default insertion, because the presence of $\mathrm{H}$ in the stem does not lead to an OCP violation. Therefore, even in this case, $\mathrm{H}$ triggers an $\mathrm{L}$, and $\mathrm{L}$ triggers an $\mathrm{H}$ - the standard case of polarity. The difference from the usual case of polarity is that this is subtonal: the polarity holds between tone features, not between whole tones.

The case discussed above provides further evidence for the use of tone features. Not only are there natural classes showing the subtonal divisions, but the subtonal features, like any other features, are also involved in the phonology, in this case by showing dissimilation amongst themselves.

\subsection{OT implementation}

In order to present the OT analysis of the data, I first look at the easier pattern, the assimilating suffixes, which requires a smaller list of constraints. Building on this, I will then present the more complex data with the quirky assimilating suffixes. Finally, I consider how the proposed constraint ranking accounts for the non-alternating suffixes, to verify that the OT grammar works well with all the data presented in this paper.

3.2.1 Analysis of the assimilating suffixes. I start by considering $/ z$ é-3ə/ $\rightarrow$ [zé-zá] from the assimilating set in (7a). As we saw in (9), the suffix lacks a TRN specification, and the unspecified node becomes associated to the register feature from the previous syllable. This association is triggered by the high-ranked constraint in (13), equivalent to Yip's (2002) Specify-T. 
(13) $\operatorname{Spec}(\bullet)$

Assign a violation for every TRN that is not specified with a tone feature.

We also require the $*$ NodeSHARE constraint in (14), which specifies that a tone feature associated to the TRN in one syllable should not be linked to a TN from another syllable. As straightforward spreading of features between planes or tiers is not found, this constraint is needed to prohibit such interactions. The representations proposed in this paper allow interaction between features (or nodes) on the register and the melody tiers, as a result of features being able to occur on more than one tier. Other approaches have used separate features in each tier - for example, Yip (1980) uses [ \pm Upper] for register and [ \pm high] for melody - meaning that this interaction is not possible. The constraint in (14) dictates that when a feature is specified, its function as either a melody or a register feature must be retained. A register feature may therefore be shared between the TRNs of two TBUs - as in the case of the assimilating suffixes in (9) and theoretically even between the TNs of two TBUs; however, it is marked for a feature to be shared between the TN of one TBU and the TRN of another.

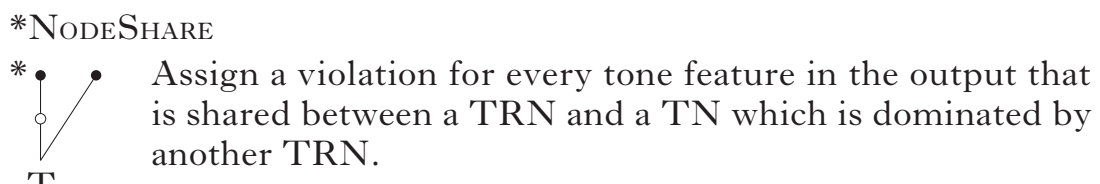
is shared between a TRN and a TN which is dominated by another TRN.

These constraints in (14) and (15) are more highly ranked than the faithfulness constraints $\operatorname{DEP}(\mathrm{H})$ and $\operatorname{DEP}(\mathrm{L})$, which prohibit the epenthesis of the $\mathrm{H}$ and $\mathrm{L}$ features respectively, as well as *Assoc, which is a faithfulness constraint prohibiting any additional association lines. These constraints, from Yip (2002), are formally defined in (15).

(15) a. $\operatorname{Dep}(\mathrm{H})$

Assign a violation for every inserted $\mathrm{H}$ tone feature.

b. $\operatorname{Dep}(\mathrm{L})$

Assign a violation for every inserted $\mathrm{L}$ tone feature.

c. *Assoc

Assign a violation for every new association line.

The evaluation for $\mid z$ zé-zə/ $\rightarrow$ [zé-ż́] in (17) requires the ranking in (16).

(16) $\operatorname{Spec}(\bullet),{ }^{*} \operatorname{Node} \operatorname{Share} \gg \operatorname{Dep}(\mathrm{H}), \operatorname{Dep}(\mathrm{L})$, *Assoc

The faithful candidate (a) has a fully specified stem and an underspecified suffix, with the TN specified as $\mathrm{H}$. The unspecified TRN in the suffix needs to be specified, and (a) is therefore eliminated by $\operatorname{Spec}(\bullet)$. The 
need for specification triggers the association of the register feature of the stem to the TRN of the suffix, as in (b). This association is better than the epenthesis of a new feature, as in (c) and (d). The association of the melody feature on the TN of the stem to the empty TRN of the suffix (e) is blocked by *NodeShare. Candidate (b) ultimately emerges as the winning candidate.

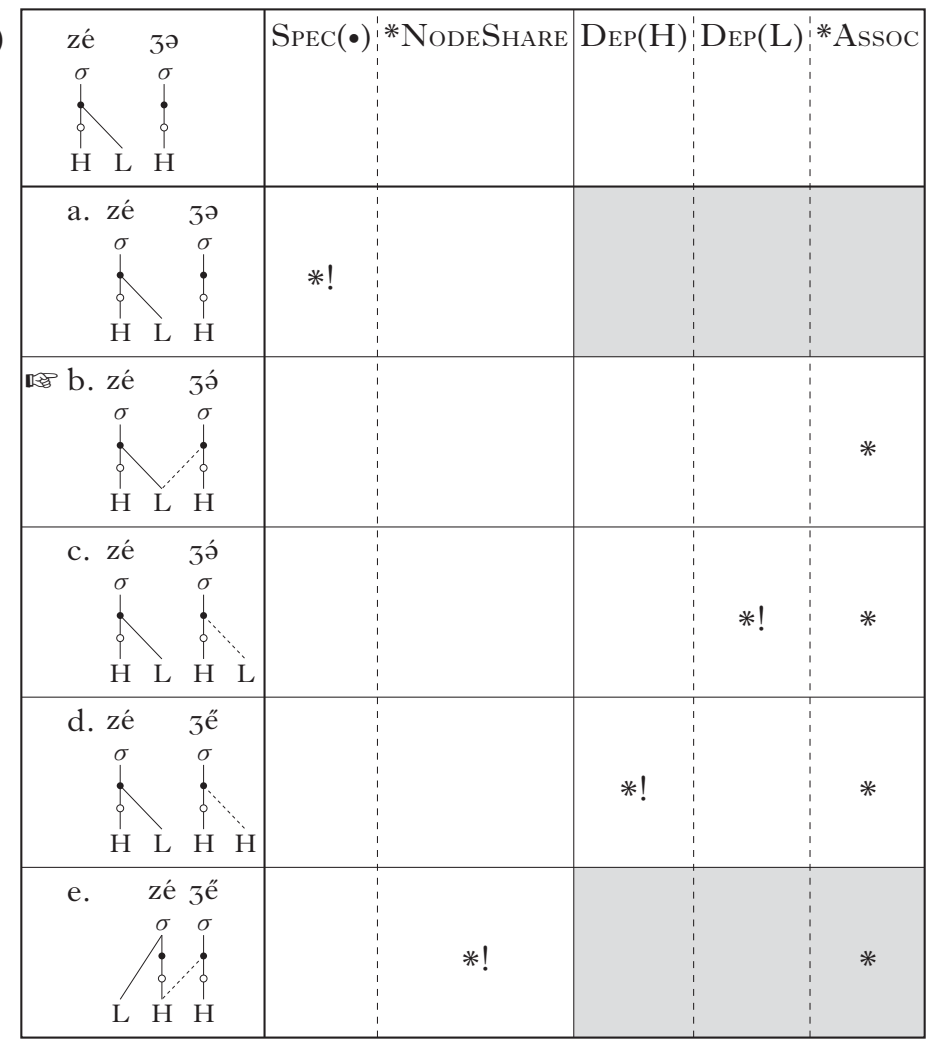

Similar evaluations will generate the other forms in (4), where the tone feature on the TRN of the stem is linked to the TRN of the underspecified suffix, resulting in raising or lowering of the suffix, depending on the register feature of the stem.

3.2.2 Analysis of the quirky alternating suffixes: default epenthesis. I now turn to the more complex pattern found in the quirky alternating suffixes in (10). I start by considering the instances in (10a), [zë-liè] and [zé-liè], with the higher stem tones and a Low suffix tone, as in (12). A new constraint is required here, one which prevents the association of a tone feature to the TRN when the TRN dominates a TN specified an L. In other words, this constraint, given in (18), says 'don't associate to a syllable with L specified to its TN', and captures 


\section{Savio M. Meyase}

the observation that suffixes like -lie do not share tone features with the stem.

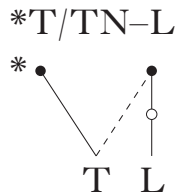

Assign a violation for every TRN-linked tone feature that is associated to another TRN dominating a TN which in turn dominates an $\mathrm{L}$.

(18) is a language-specific constraint, and is a conjunction of a faithfulness constraint, with regards to the association, and a markedness constraint, with regards to the marked output structure.

The evaluation for /zé-lie/ $\rightarrow$ [zé-liè] is given in (19). As in (17), the faithful candidate (a) has an underspecified suffix. Here, epenthesis of the default feature $\mathrm{L}$ generates the winning candidate, (b), because association of any feature from the stem to the suffix is not possible. This results in the overall Low tone in the suffix. ${ }^{*} \mathrm{~T} / \mathrm{TN}-\mathrm{L}$ is also high-ranked, along with $\operatorname{Spec}(\bullet)$ and $* \operatorname{NodeShare.~However,~we~need~to~tweak~the~ranking~in~}$ (19) by ranking $\operatorname{Dep}(\mathrm{H})$ above $\operatorname{Dep}(\mathrm{L})$, to reflect the default epenthesis of the $\mathrm{L}$ feature.

\begin{tabular}{|c|c|c|c|c|c|c|}
\hline 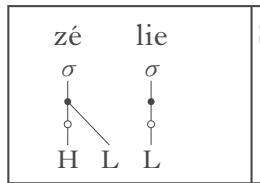 & $\operatorname{SpEC}(\bullet)$ & *NodeShare & *T/TN-L & $\operatorname{Dep}(\mathrm{H})$ & Dep(L) & Assoc \\
\hline 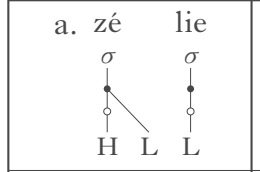 & *! & & & & & \\
\hline 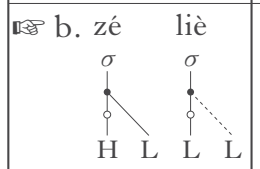 & & & & & * & * \\
\hline 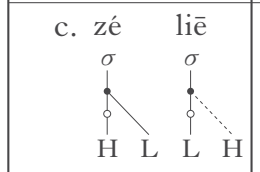 & & & & $* !$ & & $*$ \\
\hline \begin{tabular}{|ccc} 
d. zé & & liè \\
$\sigma$ & & $\sigma$ \\
$\vdots$ & $\vdots$ \\
$\vdots$ & 0 \\
$\mathrm{H}$ & $\mathrm{L}$ & $\mathrm{L}$
\end{tabular} & & & $* !$ & & & $*$ \\
\hline 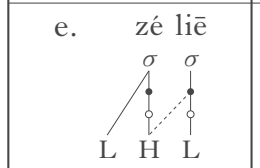 & & *! & & & & $*$ \\
\hline
\end{tabular}


The evaluation for $/$ zë-lie $/ \rightarrow$ [zë-liè] works in exactly the same way, with insertion of $\mathrm{L}$ in the underspecified suffix.

* $\mathrm{T} / \mathrm{TN}-\mathrm{L}$ differentiates the two kinds of suffixes on the basis of the specified feature. For a suffix bearing an $\mathrm{H}$ on the $\mathrm{TN}$, this constraint is vacuously satisfied and therefore enables association, making it assimilatory, while, for a suffix bearing an $\mathrm{L}$ in the $\mathrm{TN}$, it prevents association, thereby eventually enabling epenthesis.

3.2.3 Analysis of the quirky alternating suffixes: the OCP. I now turn to the central case of this research, where we formalise the OCP as a constraint explaining the polar tone output. The case in point is the set in (10b), [zē-liē] and [zè-liē], where a Mid tone is found after the two lower tones. Here we need a constraint that disallows the insertion of $\mathrm{L}$, instead inserting $\mathrm{H}$, and thereby specifying the suffix as Mid. In order to achieve this, we need a constraint that is ranked higher than $\operatorname{Dep}(\mathrm{H})$. For this, we employ the OCP. If we assume a constraint $\mathrm{OCP}(\circ-\mathrm{L})$, which bars adjacent TNs associated with $\mathrm{L}$ (crucially not just a constraint $\mathrm{OCP}(\mathrm{L})$ ), the insertion of a TN bearing an $\mathrm{H}$ (as in (11b) above) generates the desired output. The OCP constraint is given in (20).

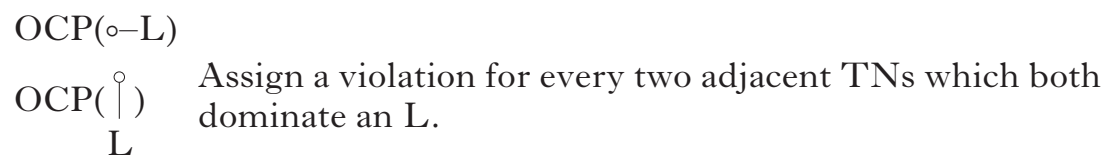

Assign a violation for every two adjacent $\mathrm{TNs}$ which both dominate an $\mathrm{L}$.

A related constraint, $\mathrm{OCP}(\circ-\mathrm{H})$, is also assumed, but is much lowerranked in the language, and is therefore not included in the tableaux.

The constraint in (20) forms the crux of the investigation here. I use the OCP to explain the tone polarity pattern involving the insertion of $(\circ-\mathrm{H})$, thereby showing why an $\mathrm{H}$ is found in the presence of the polar environment L. In so doing, I avoid the use of all-powerful constraints such as Polar (Cahill 2004) (discussed in \$4.3) to produce the pattern.

This constraint is paired with the lower-ranked constraint $\operatorname{DEP}(\circ)$, which assigns violations for instances of epenthesis to the TN (०).

At this point, we can generalise $\operatorname{SPEC}(\bullet)$ so that it holds not just for the TRN but also for the TN, as in (21).

(21) $\operatorname{Spec}(\bullet / 0)$

Assign a violation for every unspecified node.

This constraint also prevents the insertion of any node which does not have a tone feature specified to it.

The evaluation for /zè-lie $/ \rightarrow$ [zè-liē] is presented in (22). In this case, the faithful candidate violates a second high-ranked constraint, $\mathrm{OCP}(\circ-\mathrm{L})$, and a TN associated with $\mathrm{H}$ has to be inserted to avoid violating it. This $\mathrm{H}$ is linked to the empty node, thereby resulting in the suffix tone being a fully 
136 Savio M. Meyase

specified Mid. In the tableau, (c), which does not violate the OCP, is the winning candidate.

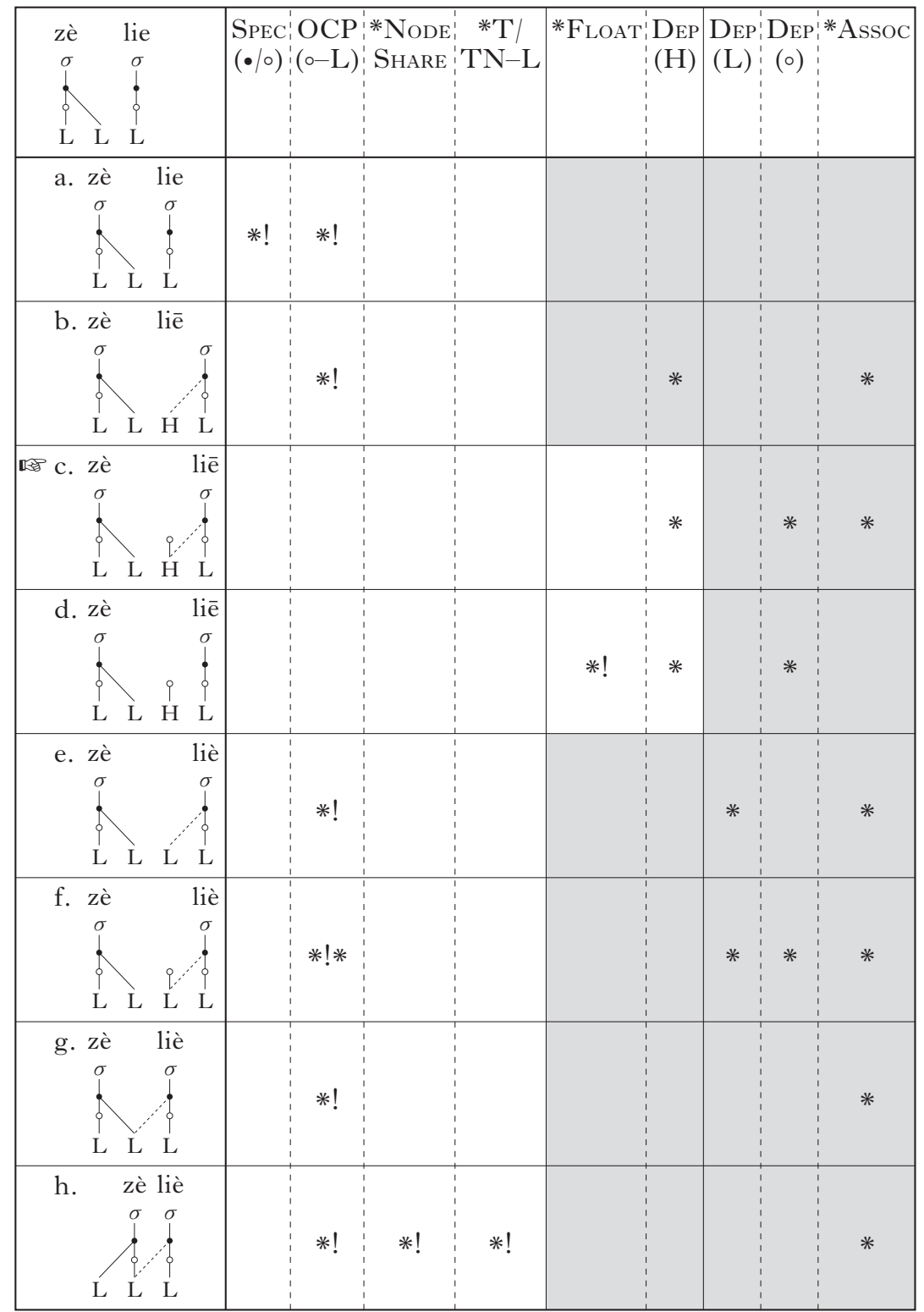

A potential candidate not included in (22) involves the epenthesis of just (o) instead of $(\circ-\mathrm{H})$. This avoids violating $\mathrm{OCP}(\circ-\mathrm{L})$, but the candidate would be immediately rejected as an optimal candidate because it violates 
the highest-ranking constraint, $\operatorname{SPEC}(\bullet /)$, as it is not specified for any tone feature. Epenthesis of just $(\circ-\mathrm{H})$ without adding association lines, as in candidate (d) (which, like (c), does not violate $\mathrm{OCP}(\mathrm{o}-\mathrm{L})$ ), violates *FLOAT, defined in (23). This constraint is high-ranked, but is lower than $\operatorname{SPEC}(\bullet / \circ)$ and $\operatorname{OCP}(\circ-\mathrm{L})$.

*FLOAT

Assign a violation for every floating feature.

3.2.4 OT analysis for non-alternating suffixes. Finally, I consider the first dataset, the non-alternating suffixes (3), which involve no tonal changes. I assume that these suffixes are fully specified for tone, and so their tones do not change. The question then arises as to how the OCP behaves in this case. Given the constraint ranking, $\mathrm{OCP}(\mathrm{o}-\mathrm{L})$ is satisfied in the same way as in (23), by inserting $(\mathrm{o}-\mathrm{H})$, as in candidate (24c). However, in this case there are no unspecified nodes available in the suffix for the epenthesised segment to associate to. It remains floating, without causing any phonetic change to the suffix.

The faithful candidate, (a), violates $\mathrm{OCP}(\mathrm{o}-\mathrm{L})$, with both syllables having an L associated with the TN. Repairing the OCP by inserting just the $\mathrm{TN}$, as in (b), violates the constraint demanding specification of the TN. Candidate (c) satisfies $\mathrm{OCP}(\circ-\mathrm{L})$ by inserting a TN associated with an $\mathrm{H}$, creating a floating node which is not associated to any syllable; the phonetic output tone is not affected.

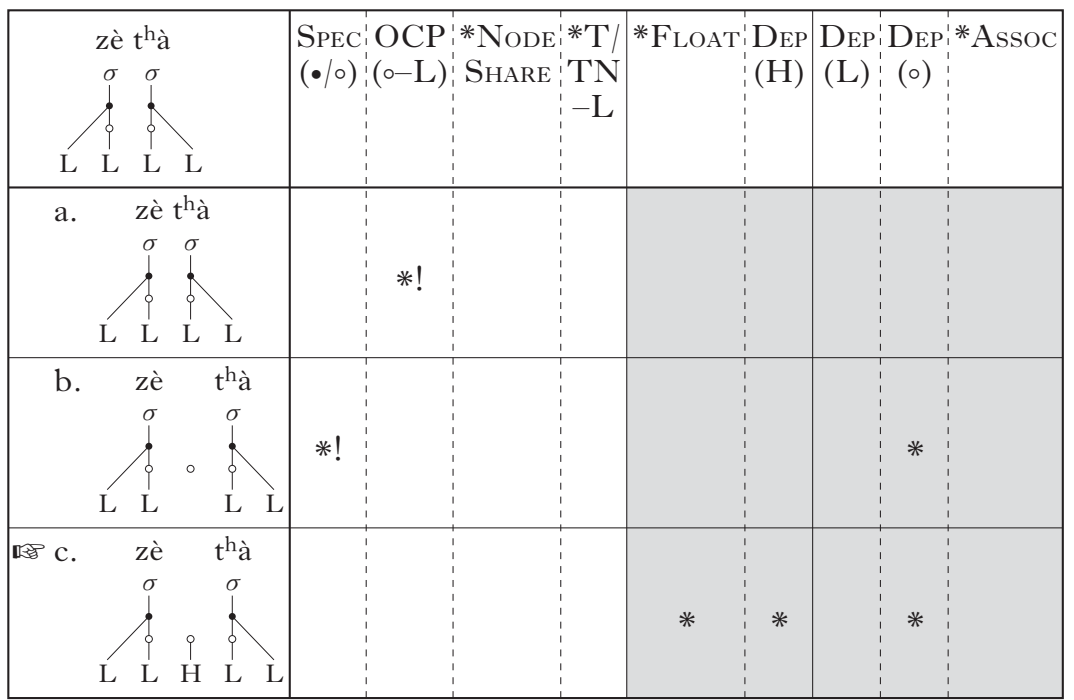




\section{Comparison with other approaches}

\subsection{Representations with features only}

The tone features of Yip (1980) and Pulleyblank (1986) can be applied to Tenyidie by first dividing the four tones into two registers consisting of the higher two tones and the lower two tones respectively, using the feature [ \pm Upper]. Each register is then further subdivided by the feature [ \pm high], the melody (or the pitch/tone) feature. As shown in Table I, this provides a representation which correctly characterises for the natural classes identified above.

\begin{tabular}{|l|c|c|}
\hline register & melody & \multicolumn{1}{|c}{} \\
\hline \multirow{2}{*}{ + Upper } & + high & Extra High \\
\cline { 2 - 3 } & - high & High \\
\hline \multirow{2}{*}{ - Upper } & + high & Mid \\
\cline { 2 - 3 } & - high & Low \\
\hline
\end{tabular}

Table I

Tonal decomposition (Yip 1980).

Using this representation, one can account for the assimilating suffixes with a rule spreading of the melody feature, as in (25).

(25) Spreading of [ \pm high] in assimilating suffixes

$$
\left[\begin{array}{c}
+ \text { Upper } \\
\varnothing
\end{array}\right] \rightarrow\left[\begin{array}{l}
+ \text { Upper } \\
\alpha \text { high }
\end{array}\right] /[\alpha \text { high }]
$$

However, the quirky alternating suffixes prove difficult, as we would have to resort to the use of an alpha rule comparing values across different features, as in Gregersen (1974), where the value of the register is flipped and applied to the melody, giving (26).

(26) Cross-feature polarity in quirky alternating suffixes

$$
\left[\begin{array}{c}
- \text { Upper } \\
\varnothing
\end{array}\right] \rightarrow\left[\begin{array}{l}
- \text { Upper } \\
\alpha \text { high }
\end{array}\right] /[-\alpha \text { Upper }]
$$

As we have seen, the formulation in (26) entails that polarity is a phonological process in itself. It employs a powerful mechanism where polarity is seen as a does-it-all tool to derive the end product. The alpha notation can be used for any number of combinations between any two unrelated features in the system in the formulation of a rule. This makes the rule too powerful, and the notation has been frowned upon in recent literature. 


\subsection{Autosegmental representation without nodes}

If the tones in Tenyidie were to be represented without nodes, they would look like the autosegmental representations of Clements (1983). In such a model, the four tones have the representations in (27).

(27) Representation of tones without nodes

$\begin{array}{cccc}\text { Extra High } & \text { High } & \text { Mid } & \text { Low } \\ \sigma & \sigma & \sigma & \sigma \\ \mid & \mid & \mid & \mid \\ \mathrm{H} & \mathrm{H} & \mathrm{L} & \mathrm{L} \\ \mathrm{H} & \mid & \mid & \mid\end{array}$

The underspecified suffixes are represented as syllables consisting of a single feature, as in (28).

(28) Underspecified suffixes

a. Assimilating suffix

b. Quirky alternating suffix
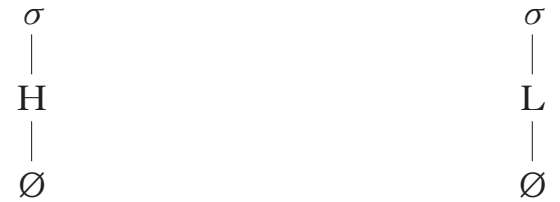

The analysis of assimilating suffixes is similar even in this case, with the feature of the stem spreading to replace the unspecified feature in the assimilating suffix, as in (29a) for $\mid$ zè-zə/ $\rightarrow$ [zè-zá].

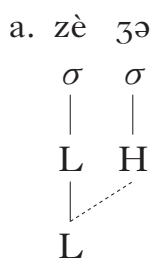

b. zè

lie

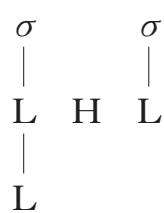

The analysis of the quirky alternating suffix, on the other hand, is more complicated. Given $\mathrm{OCP}(\mathrm{L})$, epenthesis of $\mathrm{H}$ will take place on the register tier, as shown in (29b) for /zè-lie/ $\rightarrow$ [zè-liē]. The epenthesised H is moved down to the melody tier, which is realised in the suffix, giving [liē], with a Mid tone. This, however, presents a problem, in that it allows a feature to change its affiliation from one tier to another. Although the use of nodes, as in this paper, adds more machinery to the representation and therefore makes the model more powerful, it avoids the problem of features switching tiers, as the features are associated to fixed nodes. 
Another disadvantage of the analysis without nodes is that it requires a two-step process. The first process is the default or OCP-triggered epenthesis, depending on the context. The second step, as in (29b), is the relocation of the epenthesised $\mathrm{H}$. Such an analysis has also been proposed in Stratal Phonology and Stratal OT (Kiparsky 2000, Bermúdez-Otero 2018). However, there is no other morphological evidence in Tenyidie to suggest that the use of strata is needed.

\subsection{Non-phonological morphological alternations}

An alternative way of looking at the polarity pattern could be that the tone alternation is just a case of special allomorphs being sensitive to the class of the stems. However, there is no evidence for the presence of classes in Tenyidie suffixes, and suffixes can be stacked up to show that the tonal pattern observed is purely phonological in nature. This is shown in $\$ 6$.

The tone polarity analyses of Cahill (2004) and Hantgan (2009) depend on the constraint POLAR, which is defined very specifically on the plural morpheme. Cahill's definition is: 'in a Noun Class 1 plural, the last tone of the plural is opposite in value to the immediately preceding tone'. The Agreement by Correspondence analysis of tone polarity in Shih \& Inkelas (2019) also depends on a morpheme-specific constraint, $[\alpha \mathrm{T}]$ $[\alpha \mathrm{T}]$-EdGE $(\mathrm{Pl})($ where 'Pl' = 'plural'), which prohibits correspondence across a plural morpheme boundary. Related to these analyses are approaches in which polarity can be accounted for in terms of cophonologies (Orgun 1996, Anttila 2002, Inkelas \& Zoll 2007) or indexed constraints in Morpheme-Specific Phonology (Pater 2007).

The advantage of my approach to tone polarity over the abovementioned approaches is that, with the help of the tonal representation, the phenomenon can be analysed as purely phonological.

\section{Polarity as an epiphenomenon}

I have shown that the tone polarity observed in Tenyidie is actually an epiphenonemon, a reflex of OCP-driven epenthesis. The claim in this paper is that polarity in Tenyidie is merely a surface phenomenon, and that a linguistic mechanism of polarity triggering opposite values of adjacent elements is not necessary. This analysis is thus more economical. In addition, treating polarity as a reflex rather than a mechanism is preferable because the phenomenon is analysable on purely phonological terms, and there is no need to make reference to the morphology of the constituents. The Tenyidie case thus contributes to a body of evidence showing that many apparent cases of polarity are in fact best analysed by other means.

The debate on the existence of 'true polarity' (i.e. polarity as a mechanism) began with Kenstowicz et al. (1988), where tone polarity was analysed as a reflex of the OCP. The absence, or at least the rarity, of true polarity in the world's languages raises doubts about the need for such a phenomenon (Trommer 2007, Bye 2010, de Lacy 2012). The use of alpha notation is 
considered too 'powerful' in de Lacy (2012). In the context of Tenyidie tone, the use of this notation can also be seen as too powerful, as this would imply that that features in different tiers can polarise each other, or as shown in $\$ 4.1$, that polarity is found across features. A grammatical model of this sort would have wider undesirable consequences, such as predicting that any two different features could interact: for example [+fricative] might trigger [-voice], or vice versa. This would be too powerful, and also arbitrary, on the assumption that feature values are only conventions based on the names chosen for the feature - for instance, [-voice] could well have been [+voiceless]. The debate on phenomenon vs. epiphenomenon continues in morphophonological studies, with DiCanio et al. (2020) arguing for an exchange rule (non-tonal) in Itunyoso Triqui, a claim which is countered by de Lacy (2020).

Mòoré, the classic case of tone polarity as an epiphenomenon (see the data in (1) above), was analysed with the use of a Meeussen's Rule type of dissimilation, where $\mathrm{HH} \rightarrow \mathrm{HL}$, on the assumption that all suffixes were specified as underlyingly $\mathrm{H}$. As a result, we find the sequence $\mathrm{LH}$ by default when the stem is $\mathrm{L}$, but HL when the stem is $\mathrm{H}$, resulting in surface tone polarity. Here, polarity is a result of the OCP changing an underlyingly given structure. Tenyidie is slightly different, since we have assumed that the suffix is underspecified. In this case, surface polarity arises because of the epenthesis of the polar feature as a result of the OCP, filling up an underlyingly unspecified unit. This is akin to Anttila \& Bodomo's (2000) analysis of Dagaare, which has a similar polarity pattern to Mòoré. In their analysis, $\mathrm{LH}$ is the result of an $\mathrm{L}$ stem and a tonally unspecified suffix, with default epenthesis of $\mathrm{H}$, while HL is the result of an $\mathrm{H}$ stem and a tonally unspecified suffix, with epenthesis of a non-default $\mathrm{L}$ as a consequence of an $\mathrm{OCP}(\mathrm{H})$ violation.

\section{Stacking suffixes}

The proposed representation also makes predictions as to how tones will change when suffixes are stacked, and these predictions are correctly borne out. (30) gives the derivation of a form containing the perfective $-t a$, an assimilating suffix, and two occurrences of the irrealis -lie, a quirky alternating suffix.

(30) lè ta lie lie $\rightarrow$ lè-tá-liè-liē 'Get gone down!'

go.down PFV IRR IRR

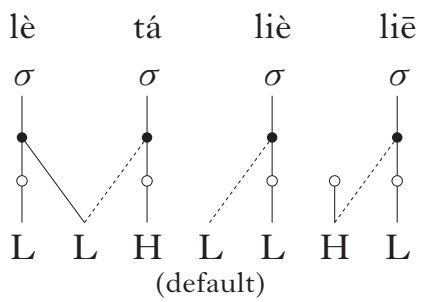




\section{Savio M. Meyase}

Only the stem is fully specified; the TRNs of the three suffixes are unspecified. All the suffixes behave individually as they do when they are in a stem-suffix pair. The spreading of the register tone is seen in the suffix $-t a$, the default insertion of $\mathrm{L}$ in the first -lie, and the insertion of the $\mathrm{TN}$ with an $\mathrm{H}$ in the last suffix.

The language allows for the suffixes in (30) to be rearranged as /lè-lie-talie/, as in (31), with a slight change in meaning. In this construction, tonal change in the suffixes is again based only on the tone of the immediately preceding syllable, showing that the tonal change is purely phonological.

(31) lè lie ta lie $\rightarrow$ lè-liē-tä-liè 'Get gone down!'

go.down IRR PFV IRR

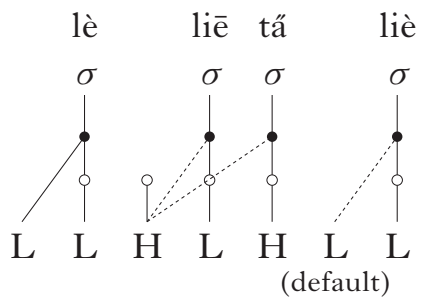

Here $\mathrm{OCP}\left(\mathrm{o}_{-} \mathrm{L}\right)$ applies between the stem and the first suffix, hence the insertion of the TN associated with $\mathrm{H}$. This forms the register feature of the first suffix. The second suffix, $-t a$, an assimilating suffix, borrows the register feature of the first suffix by spreading of $\mathrm{H}$. The third suffix prohibits spreading, and the OCP is not applicable here, so that we find default L-insertion.

Changing only the stem melody tone in (31) from Low in /lè/ to Extra High in /lë/ produces a different sequence of tones in the suffixes, as there is now no OCP-triggered $\mathrm{H}$, rather default $\mathrm{L}$ epenthesis. This is demonstrated in (32).

(32) lë lie ta lie $\rightarrow$ lë-liè-tá-liè 'Get slicing!'

slice IRR PFV IRR

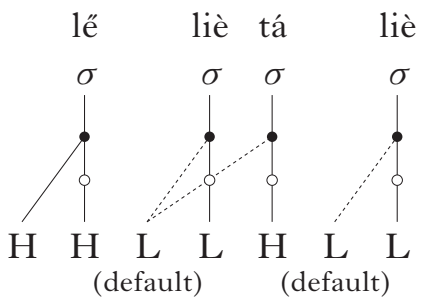

The examples in (33) show sequences of all the three kinds of suffix. The non-alternating (fully specified) suffix immediately follows the stem, and acts as the trigger for the rest of the suffixes, blocking the stems. This is followed by an assimilating suffix and finally a quirky alternating suffix. 
(33) a. sẻ fá ba tio $\rightarrow$ se̋-fá-bá-tiò 'will have been using' use PFV PROG FUT

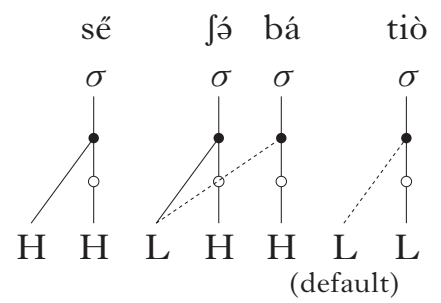

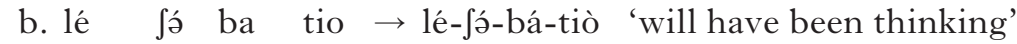
think PFV PROG FUT

c. pēdā Já ba tio $\rightarrow$ pēdā-fá-bá-tiò 'will have been blaming' blame PFV PROG FUT

d. tsà fá ba tio $\rightarrow$ tsà-fá-bá-tiò 'will have been giving' give PFV PROG FUT

The stacking data here also proves problematic for the analysis of polarity with morpheme-specific constraints. Such approaches are myopic with respect to the data here, as they only see one suffix after the stem. The Tenyidie data shows that tone polarity is iterative, and not necessarily dependent on the stem only.

\section{Conclusion}

Tenyidie has four lexical tones, which can be represented distinctively using only two tone features, $\mathrm{H}$ and $\mathrm{L}$, in a recursive autosegmental representation with a division between register and melody. The need for such a representation has been put forward in this paper, as opposed to using four independent individual features for each of the four tones.

Tenyidie has, broadly speaking, two kinds of suffixes. One kind of suffix, the non-alternating suffix, comes with its tone features specified, and displays no tonal changes on the surface. For the other kind, melody features are specified and register features are unspecified. Based on the tonal changes which these underspecified suffixes undergo, they can be further divided into two. Underspecified suffixes bearing an $\mathrm{H}$ in the melody simply borrow the register from the stem by spreading; these are the assimilating suffixes. The other kind, the quirky alternating suffixes, have an $\mathrm{L}$ in the melody. This set shows some kind of polarity, and therefore provides the core data for this paper. The data presented here adds further evidence for the analysis of tone polarity, in particular for analysing polarity in linguistics as being an epiphenomenon of the OCP, as suggested in previous work (Kenstowicz et al. 1988, Anttila \& Bodomo 2000). At the same time, this paper has also provided data showing a new kind of tone polarity, subtonal polarity. The data also shows that tone polarity is not confined to languages with two or three tones. 


\section{Savio M. Meyase}

Using evidence from Seenku, McPherson (2010) makes the claim that tone features should be preferred to tone primitives, against Hyman (2010) and Clements et al. (2010). This paper provides further evidence for tone features by showing that there are clear natural classes of tones supported by the data. The Tenyidie data also shows that these tone features drive processes of dissimilation patterns in the tone system.

\section{REFERENCES}

Akinlabi, Akinbiyi \& Mark Liberman (2000). The tonal phonology of Yoruba clitics. In Birgit Gerlach \& Janet Grijzenhout (eds.) Clitics in phonology, morphology and syntax. Amsterdam: Benjamins. 31-62.

Anttila, Arto (2002). Morphologically conditioned phonological alternations. NLLT 20. $1-42$.

Anttila, Arto \& Adams Bodomo (2000). Tonal polarity in Dagaare. In Vicki Carstens \& Frederick Parkinson (eds.) Advances in African linguistics. Trenton, NJ: Africa World Press. 119-134.

Bermúdez-Otero, Ricardo (2018). Stratal Phonology. In S. J. Hannahs \& Anna R. K. Bosch (eds.) The Routledge handbook of phonological theory. Abingdon \& New York: Routledge. 100-134.

Blankenship, Barbara, Peter Ladefoged, Peri Bhaskararao \& Nichumeno Chase (1993). Phonetic structures of Khonoma Angami. Linguistics of the Tibeto-Burman Area 16:2. 69-88.

Bye, Patrik (2010). Derivations. In Nancy C. Kula, Bert Botma \& Kuniya Nasukawa (eds.) The Continuum companion to phonology. London: Continuum. 135-173.

Cahill, Michael (2004). Tone polarity in Konni nouns. Studies in African Linguistics 33. $1-33$

Clements, G. N. (1983). The hierarchical representation of tone features. In Ivan R. Dihoff (ed.) Current approaches to African linguistics. Vol. 1. Dordrecht: Foris. 145-176.

Clements, G. N., Alexis Michaud \& Cédric Patin (2010). Do we need tone features? In Goldsmith et al. (2010) 3-24.

Creissels, Denis \& Claire Grégoire (1993). La notion de ton marqué dans l'analyse d'une opposition tonale binaire: le cas du mandingue. Fournal of African Languages and Linguistics 14. 107-154.

Cyffer, Norbert (1991). We learn Kanuri. Cologne: Rüdiger Köppe.

de Lacy, Paul (2012). Morphophonological polarity. In Jochen Trommer (ed.) The morphology and phonology of exponence. Oxford: Oxford University Press. 121-159.

de Lacy, Paul (2020). Do morphophonological exchange rules exist? A reply to Dicanio et al. (2020). Phonological Data and Analysis 2:4. 29-43. https://doi.org/10.3765/pda. v2no4.46.

DiCanio, Christian, Basileo Martínez Cruz, Benigno Cruz Martínez \& Wilberto Martínez Cruz (2020). Glottal toggling in Itunyoso Triqui. Phonological Data and Analysis 2:4. 1-28. https://doi.org/10.3765/pda.v2art4.3.

Dutta, Indranil, Mimi Kevichüsa Ezung, Shakuntala Mahanta \& Savio M. Meyase (2012). Lexical tones of Tenyidie: fundamental frequency, voice quality and pitch modeling. Paper presented at the Workshop on Tone and Intonation, IIT Guwahati.

Dwyer, David (1976). The analysis of Bambara polarization. In Larry M. Hyman, Leon C. Jacobson \& Russell G. Schuh (eds.) Papers in African linguistics in honor of Wm. E. Welmers. Studies in African Linguistics. Supplement 6. 27-38.

Evans, Jonathan P. (2008). 'African' tone in the Sinosphere. Language and Linguistics 9. $463-490$. 
Goldsmith, John A., Elizabeth Hume \& W. Leo Wetzels (eds.) (2010). Tones and features: phonetic and phonological perspectives. Berlin \& Boston: De Gruyter Mouton.

Gregersen, Edgar A. (1974). Consonant polarity in Nilotic. In Erhard Voeltz (ed.) 3rd Annual Conference on African Linguistics. Bloomington: Indiana University. 105-109.

Hantgan, Abbie (2009). Does tone polarity exist? Evidence from plural formation among Bangime nouns. Indiana University Working Papers in Linguistics 8. 69-83.

Hoffmann, Carl (1963). A grammar of the Margi language. London: Oxford University Press.

Hyman, Larry M. (1985). A theory of phonological weight. Dordrecht: Foris. Reprinted 2003, Stanford: CSLI.

Hyman, Larry M. (1993). Register tones and tonal geometry. In Harry van der Hulst \& Keith Snider (eds.) The phonology of tone: the representation of tonal register. Berlin: Mouton de Gruyter. 75-108.

Hyman, Larry M. (2007). Kuki-Thaadow: an African tone system in Southeast Asia. UC Berkeley Phonology Lab Annual Report. 1-19.

Hyman, Larry M. (2010). Do tones have features? In Goldsmith et al. (2010). 50-80.

Inkelas, Sharon \& Cheryl Zoll (2007). Is grammar dependence real? A comparison between cophonological and indexed constraint approaches to morphologically conditioned phonology. Linguistics 45. 133-171.

Kenstowicz, Michael, Emmanuel Nikiema \& Meterwa Ourso (1988). Tonal polarity in two Gur languages. Studies in the Linguistic Sciences 18. 77-103.

Kiparsky, Paul (2000). Opacity and cyclicity. The Linguistic Review 17. 351-365.

Kutsch Lojenga, Constance (2002). Tone polarity in Fur. Paper presented at the 33rd Annual Conference on African Linguistics, Athens, $\mathrm{OH}$.

Kuolie, Duovituo (2006). Structural description of Tenyidie: a Tibeto-Burman language of Nagaland. Kohima: Ura Academy Publication Division.

Lin, You-Jing (2012). By no means marginal: privative tone in Zhuokeji Rgyalrong. Language and Linguistics 13. 625-662.

McPherson, Laura (2010). Tone features revisited: evidence from Seenku. In Doris L. Payne, Sara Pacchiarotti \& Mokaya Bosire (eds.) Diversity in African languages. Berlin: Language Science Press. 5-22.

Mahanta, Shakuntala \& Amalesh Gope (2018). Tonal polarity in Sylheti in the context of noun faithfulness. Language Sciences 69. 80-97.

Meyase, Savio M. (2014). Four versus five: the number of tones in Tenyidie. In Carlos Gussenhoven, Yiya Chen \& Dan Dediu (eds.) Proceedings of the 4th International Symposium on Tonal Aspects of Languages. 19-22. Available (February 2021) at http://www.isca-speech.org/archive/tal_2014.

Meyase, Savio M. (2016). A morphological investigation of the tonal phonology of Tenyidie. PhD dissertation, English and Foreign Languages University, Hyderabad.

Newman, Paul (1995). Hausa tonology: complexities in an 'easy' tone language. In John A. Goldsmith (ed.) The handbook of phonological theory. Cambridge, MA \& Oxford: Blackwell. 762-781.

Olawsky, Knut J. (1996). An introduction to Dagbani phonology. Düsseldorf: Arbeiten des SFB.

Olson, Kenneth S. (2001). The phonology and morphology of Mono. PhD dissertation, University of Chicago.

Orgun, C. Orhan (1996). Sign-based morphology and phonology with special attention to Optimality Theory. PhD dissertation, University of California, Berkeley.

Ozerov, Pavel (2018). Tone assignment and grammatical tone in Anal (TibetoBurman). Studies in Language 42. 708-733.

Pater, Joe (2007). The locus of exceptionality: morpheme-specific phonology as constraint indexation. In Leah Bateman, Michael O'Keefe, Ehren Reilly \& Adam Werle (eds.) Papers in Optimality Theory III. Amherst: GLSA. 259-296. 


\section{Savio M. Meyase}

Picanço, Gessiane (2002). Tone polarity as phonologically conditioned allomorphy in Mundurukú. BLS 28. 237-248.

Pulleyblank, Douglas (1983). Extratonality and polarity. WCCFL 2. 204-216.

Pulleyblank, Douglas (1986). Tone in Lexical Phonology. Dordrecht: Reidel.

Schuh, Russell G. (1971). Verb forms and verb aspects in Ngizim. Fournal of African Languages 10. 47-60.

Shih, Stephanie S. \& Sharon Inkelas (2018). Autosegmental aims in surface-optimizing phonology. LI 50. 137-196.

Snider, Keith L. (1999). The geometry and features of tone. Arlington: Summer Institute of Linguistics.

Trommer, Jochen (2005). Polar tone in Kanuri. Ms. Available (February 2021) at https://home.uni-leipzig.de/jtrommer/papers/papers.html.

Trommer, Jochen (2007). Voicing polarity in Luo. Ms. Available (February 2021) at https://home.uni-leipzig.de/jtrommer/papers/papers.html.

Watkins, Justin (2013). A first look at tone in Myebon Sumtu Chin. SOAS Working Papers in Linguistics 16. 79-104.

Welmers, Beatrice F. \& William E. Welmers (1968). Igbo: a learner's dictionary. African Studies Center, University of California, Los Angeles.

Yip, Moira (1980). The tonal phonology of Chinese. PhD dissertation, MIT.

Yip, Moira (2002). Tone. Cambridge: Cambridge University Press. 